\title{
Differential Inhibitory Effects of Forskolin, Isoproterenol, and Dibutyryl Cyclic Adenosine Monophosphate on Phosphoinositide Hydrolysis in Canine Tracheal Smooth Muscle
}

\author{
J. Mark Madison and James K. Brown \\ Respiratory Care Section, Medical Service, Veterans Administration Medical Center, San Francisco, California 94121; and the \\ Cardiovascular Research Institute and Department of Medicine, University of California, San Francisco, California 94143
}

\begin{abstract}
A characteristic feature of airway smooth muscle is its relative sensitivity to relaxant effects of beta adrenergic agonists when contracted by inflammatory mediators, such as histamine, vs. resistance to these relaxant effects when contracted by muscarinic agonists. Because contractions presumably depend upon the hydrolysis of membrane phosphoinositides (PI) and the generation of inositol phosphates (IP), our goal was to test for the effects of forskolin, isoproterenol, and dibutyryl cAMP on histamine- vs. methacholine-induced IP accumulation in canine tracheal smooth muscle. Methacholine $\left(10^{-3} \mathrm{M}\right)$ was a more effective stimulant of IP accumulation (9.6 \pm 2.1 -fold increase) than equimolar histamine (3.6 \pm 0.5 -fold increase) in this tissue. When responses to equieffective methacholine (4 $\left.\times 10^{-6} \mathrm{M}\right)$ and histamine $\left(10^{-3} \mathrm{M}\right)$ were compared, neither forskolin, isoproterenol, nor dibutyryl cAMP significantly decreased IP accumulation in response to methacholine. In contrast, each of these three agents significantly decreased responses to histamine (by $56 \pm 9,52 \pm 2$, and $61 \pm 2 \%$, respectively). We concluded that, in canine tracheal smooth muscle, increased CAMP is associated with inhibition of PI hydrolysis in response to histamine but not methacholine. The findings suggest a novel mechanism for selective modulation by cAMP of receptor-mediated cellular activation.
\end{abstract}

\section{Introduction}

Beta adrenergic agonists are the mainstay of treatment for bronchospastic diseases. The relaxant effects of these agents on airway smooth muscle presumably depend upon their ability to increase intracellular cAMP in the muscle, but the precise ways in which increased cAMP inhibits muscular contraction are not known.

This paper was presented in part at the 1988 Annual Meeting of the American Thoracic Society, Las Vegas, NV.

Requests for reprints should be addressed to Dr. J. Mark Madison, Respiratory Care Section (111D), Veterans Administration Medical Center, 4150 Clement St., San Francisco, CA 94121. 1988.

Received for publication 2 May 1988 and in revised form 30 June

The Journal of Clinical Investigation, Inc.

Volume 82, October 1988, 1462-1465
A characteristic feature of airway smooth muscle is that its sensitivity to the relaxant effects of beta adrenergic agonists depends importantly on the specific contractile agonist used to induce tone $(1,2)$. For example, in canine airway smooth muscle, contractions induced by muscarinic cholinergic agonists are relatively resistant to relaxation by isoproterenol compared with contractions induced by histamine $(1,3)$.

The mechanisms underlying the differential effects of beta adrenergic stimulation on histaminergic vs. muscarinic airway smooth muscle tension are not known (1). One possibility is that increased cAMP in the smooth muscle cell inhibits the mobilization of calcium by histamine but not by muscarinic agonists (4). Increasing evidence indicates that calcium mobilization in many cells; including airway smooth muscle cells, is mediated by the products of phosphoinositide (PI) ${ }^{1}$ hydrolysis (5-10). In neutrophils, platelets, and lymphocytes, agents that increase intracellular cAMP have been shown to decrease PI hydrolysis (11-13), and these results suggest that cAMP may regulate calcium mobilization by inhibiting the generation of inositol phosphates (IP) (14).

To explain the differential effects that beta adrenergic stimulation has on airway smooth muscle contractions, we hypothesized that increased intracellular CAMP in this tissue inhibits PI hydrolysis in response to histamine but has less effect on the PI hydrolysis induced by muscarinic agonists. As the initial step in testing this hypothesis, we quantified the accumulation of IP as an indirect measure of PI hydrolysis $(15,16)$ in canine tracheal smooth muscle. The effects of forskolin, a potent stimulant of cAMP synthesis $(17,18)$, as well as isoproterenol and dibutyryl cAMP, were examined on histamine- vs. methacholine-induced PI hydrolysis in this tissue.

\section{Methods}

Adult mongrel dogs $(n=30)$ were anesthetized with pentobarbital (30 $\mathrm{mg} / \mathrm{kg}$ ) and the cervical tracheas were excised and placed immediately into ice-cold Krebs-Henseleit buffer $(\mathrm{pH}=7.4)$ containing $10^{-5} \mathrm{M}$ indomethacin (KHI). Smooth muscle was cut transversely into 1-mmwide strips. After being weighed, strips of muscle totaling $\sim 100 \mathrm{mg}$ wet wt (range 80-120 mg) were added to tubes each containing $200 \mu \mathrm{l}$

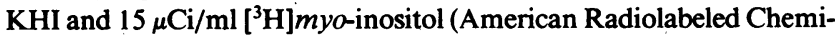
cals, St. Louis, MO). The muscle strips were incubated for $2 \mathrm{~h}$ at $37^{\circ} \mathrm{C}$.

1. Abbreviations used in this paper: $\mathrm{IP}$, inositol phosphates; $\mathrm{IP}_{1}$, myoinositol phosphate; $\mathrm{IP}_{2}$, myo-inositol bisphosphate; $\mathrm{IP}_{3}$, myo-inositol trisphosphate; KHI, Krebs-Henseleit buffer $(\mathrm{pH}=7.4)$ containing indomethacin; PI, phosphoinositide. 
In preliminary experiments, we determined that incubating tissues in $\left[{ }^{3} \mathrm{H}\right] m y o-i n o s i t o l$ for an additional $1 \mathrm{~h}$ did not increase the increment in radiolabeled IP recovered after agonist stimulation. Also, after loading for $2 \mathrm{~h}$, the accumulation of IP in response to histamine or methacholine was linear with respect to time for $15 \mathrm{~min}$.

After loading, the strips of muscle were washed three times with 2 $\mathrm{ml}$ of $\mathrm{KHI}$, then placed in $\mathrm{KHI}$ containing $10 \mathrm{mM}$ lithium chloride and either vehicle alone or vehicle plus $10^{-8}-10^{-5} \mathrm{M}$ forskolin, $10^{-8}-10^{-5} \mathrm{M}$ isoproterenol, or $10^{-3} \mathrm{M}$ dibutyryl cAMP. When the effects of isoproterenol were tested, $8 \times 10^{-4} \mathrm{M}$ ascorbate was included. After a $30-\mathrm{min}$ preincubation at $37^{\circ} \mathrm{C}, 10^{-7}-10^{-3} \mathrm{M}$ methacholine, $10^{-6}-10^{-3} \mathrm{M}$ histamine, or vehicle alone was added to the tubes (final vol $200 \mu \mathrm{l}$ ) and incubation was continued for an additional $10 \mathrm{~min}$. The reaction was stopped by adding $1 \mathrm{ml}$ ice-cold chloroform/methanol (1:2 vol/vol).

The muscle strips in each sample were homogenized for $10 \mathrm{~s}$ with an homogenizer (Tissumizer; Tekmar Co., Cincinnati, $\mathrm{OH}$ ). The aqueous soluble IP were extracted with chloroform $/ \mathrm{methanol} / \mathrm{HCl}$ and separated by anion-exchange chromatography using columns containing $1.2 \mathrm{ml}$ of AG 1-X8 anion exchange resin (formate form) (Bio-Rad Laboratories, Richmond, CA) according to the method of Berridge et al. (15). Myo-inositol and glycerophosphoinositol were eluted by washing the columns with $20 \mathrm{ml}$ of water followed by $6 \mathrm{ml}$ of $5 \mathrm{mM}$ $\mathrm{NaBO}_{4} / 60 \mathrm{mM} \mathrm{NaCOOH}$. Myo-inositol phosphate $\left(\mathrm{IP}_{1}\right)$, myo-inositol bisphosphate $\left(\mathrm{IP}_{2}\right)$, and myo-inositol trisphosphate $\left(\mathrm{IP}_{3}\right)$ then were eluted sequentially by washing each column with $15 \mathrm{ml}$ of $0.2 \mathrm{M}$ $\mathrm{NH}_{4} \mathrm{COOH} / 0.1 \mathrm{M} \mathrm{HCOOH}, 15 \mathrm{ml}$ of $0.4 \mathrm{M} \mathrm{NH}_{4} \mathrm{COOH} / 0.1 \mathrm{M}$ $\mathrm{HCOOH}$, and $7 \mathrm{ml}$ of $1 \mathrm{M} \mathrm{NH}_{4} \mathrm{COOH} / 0.1 \mathrm{M} \mathrm{HCOOH}$. Between the collection of fractions containing $\mathrm{IP}_{2}$ and $\mathrm{IP}_{3}$, the columns were washed with an additional $10 \mathrm{ml}$ of $0.4 \mathrm{M} \mathrm{NH}_{4} \mathrm{COOH} / 0.1 \mathrm{M}$ $\mathrm{HCOOH}$. A 2-ml aliquot of each fraction was combined with $18 \mathrm{ml}$ Scintiverse E (Fisher Scientific, Springfield, NJ) and counted in a liquid scintillation counter (Beckman Instruments, Inc., Fullerton, CA). We defined total IP accumulation as the sum of the radiolabeled IP recovered as $I P_{1}, I_{2}$, and $I_{P_{3}}$. To correct for small differences in the amount of tissue in each sample, we normalized data obtained from each sample to $100 \mathrm{mg}$ tissue wet wt. All experiments were performed in duplicate.

Data were expressed as the mean \pm SEM. For all experiments, $n$ represents the number of different dogs. Mean values were compared by analysis of variance, and a Newman-Keuls test was applied for multiple comparisons (19). A value of $P<0.05$ was considered statistically significant.

\section{Results}

Stimulation of PI hydrolysis by histamine and methacholine. Both methacholine $\left(10^{-7}-10^{-4} \mathrm{M}\right)$ and histamine $\left(10^{-6}-10^{-3}\right.$ M) stimulated PI hydrolysis in a concentration-dependent manner (Fig. 1). In response to either methacholine or histamine, $\mathrm{IP}_{1}, \mathrm{IP}_{2}$, and $\mathrm{IP}_{3}$ each increased and constituted $\sim 55$,
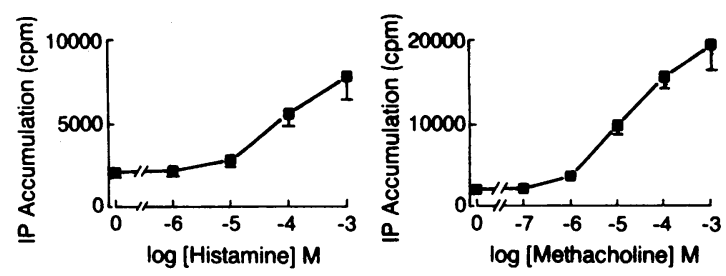

Figure 1. Effects of histamine (left) or methacholine (right) on total IP accumulation in canine tracheal smooth muscle. Muscle strips preincubated in $\left[{ }^{3} \mathrm{H}\right]$ myo-inositol for $2 \mathrm{~h}$ were exposed to either histamine or methacholine for $10 \mathrm{~min}$ in the presence of lithium chloride $(10 \mathrm{mM})$. IP were extracted and separated by anion-exchange chromatography (15). Each data point is the mean $\pm \operatorname{SEM}(n=3)$.
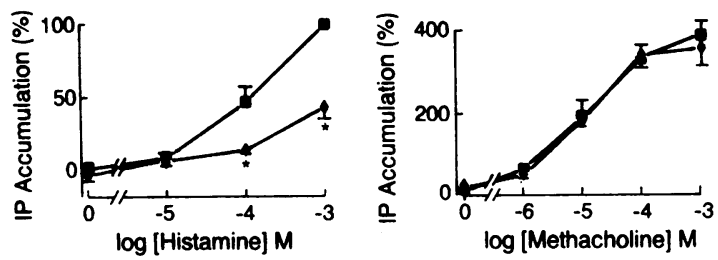

Figure 2. Differential effects of forskolin on IP accumulation. Concentration-response curves to histamine (left) or methacholine (right) were determined in the absence $(\square)$ or presence $(\bullet)$ of forskolin $\left(10^{-5}\right.$ M) $(n=3)$. In this figure, $100 \%$ IP accumulation is that increment in total IP caused by histamine $\left(10^{-3} \mathrm{M}\right)$. Total IP accumulation in the absence of agonists is designated as $0 \%$ accumulation. *Responses that were significantly less than those attained in the absence of forskolin.

42 , and 3\% of total IP, respectively. Methacholine was a more effective stimulant of PI hydrolysis than histamine. Methacholine $\left(10^{-3} \mathrm{M}\right)$ caused a $9.6 \pm 2.1$-fold increase in IP, but histamine $\left(10^{-3} \mathrm{M}\right)$ caused only a $3.6 \pm 0.5$-fold increase in IP $(n=3)$. In two experiments, PI hydrolysis in response to methacholine $\left(10^{-3} \mathrm{M}\right)$ was inhibited by atropine $\left(10^{-6} \mathrm{M}\right)$ (mean decrease of $80 \%$ ), but not by pyrilamine $\left(10^{-6} \mathrm{M}\right)$. In contrast, pyrilamine $\left(10^{-6} \mathrm{M}\right)$, but not atropine $\left(10^{-6} \mathrm{M}\right)$, inhibited PI hydrolysis in response to histamine $\left(10^{-3} \mathrm{M}\right)$ by $84 \pm 7 \%(n=3)$.

Effects of forskolin, isoproterenol, and dibutyryl cAMP on $P I$ hydrolysis. The effects of forskolin $\left(10^{-5} \mathrm{M}\right)$ on responses to histamine and methacholine are shown in Fig. 2. Forskolin decreased histamine-stimulated PI hydrolysis, but had no significant effect on methacholine-stimulated PI hydrolysis. Forskolin $\left(10^{-5} \mathrm{M}\right)$ significantly decreased the responses to $10^{-4}$ and $10^{-3} \mathrm{M}$ histamine by $55 \pm 15 \%$ and $56 \pm 9 \%(n=3)$, respectively.

Since methacholine was much more effective than histamine as a stimulant of PI hydrolysis, we compared the effects of forskolin $\left(10^{-5} \mathrm{M}\right)$ on responses to approximately equieffective concentrations of histamine and methacholine (Fig. 3, left). Achieving identical responses for histamine and methacholine in each of three experiments was difficult and, therefore, the mean response to methacholine $\left(4 \times 10^{-6} \mathrm{M}\right)$ was

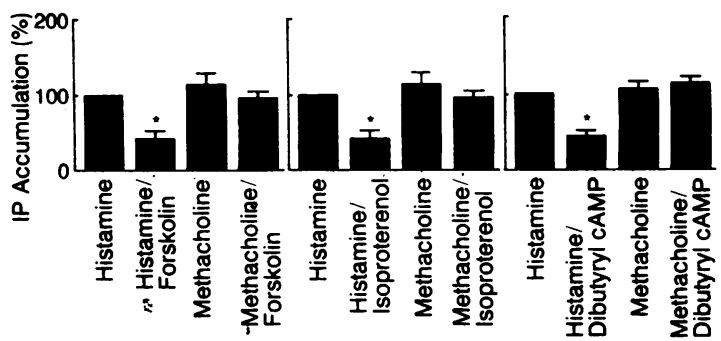

Figure 3. Differential effects of forskolin (left), isoproterenol (middle), and dibutyryl cAMP (right) on IP accumulation. In these experiments, IP accumulation in response to histamine $\left(10^{-3} \mathrm{M}\right)$ or methacholine $\left(4 \times 10^{-6} \mathrm{M}\right)$ was compared in the absence or presence of forskolin $\left(10^{-5} \mathrm{M}\right)$, isoproterenol $\left(10^{-5} \mathrm{M}\right)$, and dibutyryl cAMP $\left(10^{-3} \mathrm{M}\right)(n=3)$. In this figure, $100 \%$ IP. accumulation is that increment in total IP caused by histamine $\left(10^{-3} \mathrm{M}\right)$. Total IP accumulation in the absence of agonists is designated as $0 \%$ accumulation. *Responses that were significantly less than responses to histamine $\left(10^{-3} \mathrm{M}\right)$ alone. 
slightly higher $(7,273 \pm 450 \mathrm{cpm})$ than the response to histamine $\left(10^{-3} \mathrm{M}\right)(6,822 \pm 1,323 \mathrm{cpm})$. Forskolin significantly attenuated the response to histamine by $59 \pm 11 \%(n=3)$, but decreased the response to methacholine by only $14 \pm 8 \%$ (NS). In these same experiments, forskolin did not affect basal (unstimulated) levels of IP. The effects of forskolin on responses to histamine $\left(10^{-3} \mathrm{M}\right)$ were concentration dependent (Fig. 4, left).

In tissues treated with histamine, $\sim 65 \%$ of the forskolininduced decrease in total IP was due to a decrease in $\mathrm{IP}_{1}$, but there also were decreases in $\mathrm{IP}_{2}$ and $\mathrm{IP}_{3}$. The amount of $\mathrm{IP}_{3}$ recovered was small in these experiments using whole tissue, lithium, and 10-min incubations; therefore, detecting forskolin-induced decreases in the specific $\mathrm{IP}_{3}$ fraction was difficult. However, when data were pooled for analysis from all of the experiments shown in Figs. $2-4$, forskolin $\left(10^{-5} \mathrm{M}\right)$ caused significant decreases of $63 \pm 4,48 \pm 6$, and $29 \pm 7 \%$ in the histamine-stimulated $\mathrm{IP}_{1}, \mathrm{IP}_{2}$, and $\mathrm{IP}_{3}$ fractions, respectively.

Isoproterenol $\left(10^{-5} \mathrm{M}\right)$ and dibutyryl cAMP $\left(10^{-3} \mathrm{M}\right)$ each significantly decreased histamine-stimulated PI hydrolysis by $52 \pm 2 \%(n=3)$ and $61 \pm 2 \%(n=3)$, respectively (Fig. 3, middle and right). Isoproterenol and dibutyryl cAMP caused small mean decreases of $15 \pm 5$ and $1 \pm 12 \%$, respectively, in responses to methacholine, but these decreases were not significant. In these same experiments, basal values for IP accumulation were not significantly changed either by isoproterenol $(4 \pm 27 \%$ increase) or by dibutyryl cAMP ( $11 \pm 6 \%$ decrease). The effect of isoproterenol on histamine-stimulated PI hydrolysis was concentration dependent, with a maximal effect occurring at $10^{-5}$ $\mathrm{M}$ and a half-maximal effect occurring at $\sim 2 \times 10^{-7} \mathrm{M}$ (range $5 \times 10^{-8}-4 \times 10^{-6} \mathrm{M}, n=4$ ) (Fig. 4, right).

\section{Discussion}

In this study, as an index of agonist-induced PI hydrolysis in airway smooth muscle, we measured the accumulation of IP in lithium-treated strips of canine tracheal smooth muscle. Forskolin, isoproterenol, and dibutyryl cAMP each inhibited the PI hydrolysis that occurred in response to histamine by as much as $50 \%$, but had little or no effect on responses to methacholine. To our knowledge, this differential regulation of agoniststimulated PI hydrolysis by agents acting via the cAMP cascade has not been described previously. The finding suggests a novel mechanism by which cAMP may selectively modulate

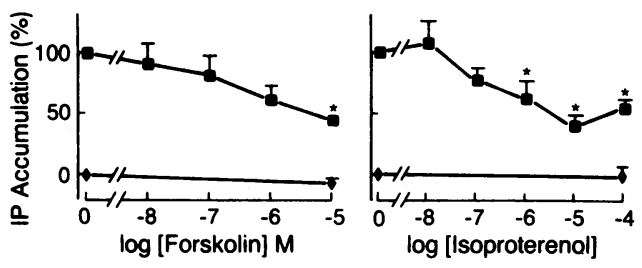

Figure 4. Concentration-response curves for the effects of forskolin (left) and isoproterenol (right) on histamine-induced IP accumulation. Accumulation of IP under basal conditions ( $\bullet)$ and in response to histamine $\left(10^{-3} \mathrm{M}\right)(\square)$ was determined in the absence (control) and presence of different concentrations of either forskolin or isoproterenol $(n=4)$. In this figure, $100 \%$ IP accumulation is that increment in total IP caused by histamine $\left(10^{-3} \mathrm{M}\right)$. Total IP accumulation in the absence of agonists is designated as $0 \%$ accumulation. *Responses that were significantly less than control. receptor-mediated activation of cells. Furthermore, in airway smooth muscle, these differential effects of forskolin, isoproterenol, and dibutyryl cAMP on PI hydrolysis are paralleled by previous demonstrations that each of these agents much more effectively relaxes histaminergic than muscarinic contraction $(1,20)$. Taken together, the findings suggest, but do not establish, that modulation of PI hydrolysis is one mechanism by which increased cAMP relaxes airway smooth muscle.

In our experiments, the fact that forskolin, isoproterenol, and dibutyryl cAMP each decreased PI hydrolysis in response to histamine suggested that increased intracellular cAMP mediated the inhibition of histamine-induced PI hydrolysis in canine tracheal smooth muscle $(17,18,21)$. Similar observations have been made previously in neutrophils, platelets, and lymphocytes (11-13). It has been proposed that increased cAMP inhibits phosphatidylinositol kinase, the enzyme that catalyzes the conversion of the membrane lipid phosphatidylinositol into phosphatidylinositol monophosphate $(22,23)$. Thus, increased cAMP may regulate the availability of substrates for hydrolysis by phospholipase C.

The ways by which cAMP differentially attenuates PI hydrolysis in response to histamine, but not methacholine, are not known. Recently, we showed that muscarinic agonists decreased adenylate cyclase activity in membranes prepared from canine tracheal smooth muscle (18). Muscarinic inhibition of adenylate cyclase would decrease the amount of cAMP generated in response to isoproterenol and forskolin and, therefore, blunt the ability of isoproterenol or forskolin to regulate PI hydrolysis. However, in our experiments, a large concentration of an applied cAMP analogue also caused differential attenuation of PI hydrolysis, inhibiting responses to histamine but not to methacholine (Fig. 3, right). This result suggests that inhibition of CAMP synthesis by methacholine may not explain the lack of effect of forskolin and isoproterenol on methacholine-stimulated PI hydrolysis.

Our experiments have not addressed other important possibilities. Potentially, the selective effect of cAMP on PI hydrolysis may be due to differential regulation by cAMP of agonist-specific pools of membrane polyphosphoinositide substrates, or may reflect compartmentation of phospholipase $\mathrm{C}$ (24). Also, cAMP may differentially modulate calcium fluxes induced by different agonists; transmembrane calcium flux, in turn, may be important in regulating portions of the phosphatidylinositol cycle (25). Selective effects of cAMP on membrane receptors (26) or on GTP-binding proteins that couple the receptors to phospholipase $\mathrm{C}$ also are possible. Finally, a large muscarinic receptor reserve may contribute to the observed differences in sensitivity to cAMP between responses to histamine and responses to methacholine $(27,28)$.

Our findings do not agree with those of a prior study in which exposure of bovine tracheal smooth muscle to isoproterenol did not alter the PI hydrolysis that occurred in response to histamine, carbachol, or serotonin (29). We cannot account for this discrepancy. One methodologic difference was a relatively prolonged (45-min) stimulation of the tissues with histamine in the previous study vs. the 10 -min stimulation used in our study.

In summary, we have shown that in airway smooth muscle, histamine-stimulated PI hydrolysis was attenuated by forskolin, isoproterenol, and dibutyryl cAMP. In contrast, comparable levels of methacholine-stimulated PI hydrolysis were not affected significantly by any of these agents. Based on our 
measurement of total IP accumulation as an index of PI hydrolysis in whole tissue, we cannot exclude a small, but potentially important, effect of isoproterenol on methacholine-induced PI hydrolysis. However, our study has established that there are very large differences between the modulatory effects of cAMP on muscarinic vs. histaminergic PI hydrolysis in canine tracheal smooth muscle. The findings suggest a novel mechanism for selective modulation by cAMP of receptormediated activation of cells. The extent to which inhibition of PI hydrolysis is important in cAMP-mediated relaxation of airway smooth muscle, and the precise way in which the selective modulation occurs, remain to be determined.

\section{Acknowledgments}

This work was supported by the Research Service of the Veterans Administration and by U. S. Public Health Service grant HL-27669. Dr. Madison is the recipient of a Research Associate Award under the Career Development Program of the Veterans Administration.

\section{References}

1. Russell, J. A. 1984. Differential inhibitory effect of isoproterenol on contractions of canine airways. J. Appl. Physiol. 57:801-807.

2. Torphy, T. J. 1984. Differential relaxant effects of isoproterenol on methacholine- versus leukotriene $\mathrm{D}_{4}$-induced contraction in the guinea-pig trachea. Eur. J. Pharmacol. 102:549-553.

3. Jenne, J. W., T. K. Shaughnessy, W. S. Druz, C. J. Manfredi, and R. E. Vestal. 1987. In vivo functional antagonism between isoproterenol and bronchoconstrictants in the dog. J. Appl. Physiol. 63:812-819.

4. Anderson, W. H., J. J. Krzanowski, J. B. Polson, and A. Szentivanyi. 1983. The effect of prostaglandin $E_{2}$ on histamine-stimulated calcium mobilization as a possible explanation for histamine tachyphylaxis in canine tracheal smooth muscle. Naunyn-Schmiedebergs Arch. Pharmakol. 322:72-77.

5. Abdel-Latif, A. A. 1986. Calcium-mobilizing receptors, polyphosphoinositides, and the generation of second messengers. Pharmacol. Rev. 38:227-272.

6. Grandordy, B. M., F. M. Cuss, A. S. Sampson, J. B. Palmer, and P. J. Barnes. 1986. Phosphatidylinositol response to cholinergic agonists in airway smooth muscle: relationship to contraction and muscarinic receptor occupancy. J. Pharmacol. Exp. Ther. 238:273-279.

7. Baron, C. B., M. Cunningham, J. F. Strauss III, and R. F. Coburn. 1984. Pharmacomechanical coupling in smooth muscle may involve phosphatidylinositol metabolism. Proc. Natl. Acad. Sci. USA. 81:6899-6903.

8. Hashimoto, T., M. Hirata, and Y. Ito. 1985. A role for inositol 1, 4, 5-trisphosphate in the initiation of agonist-induced contractions of dog tracheal smooth muscle. Br. J. Pharmacol. 86:191-199.

9. Takuwa, Y., N. Takuwa, and H. Rasmussen. 1986. Carbachol induces a rapid and sustained hydrolysis of polyphosphoinositide in bovine tracheal smooth muscle measurements of the mass of polyphosphoinositides, 2-diacylglycerol, and phosphatidic acid. J. Biol. Chem. 261:14670-14675.

10. Ducan, R. A., J. J. Krzanowski, Jr., J. S. Davis, J. B. Polson, R. G. Coffey, T. Shimoda, and A. Szentivanyi. 1987. Polyphosphoinositide metabolism in canine tracheal smooth muscle (CTSM) in response to a cholinergic stimulus. Biochem. Pharmacol. 36:307-310.
11. Kaibuchi, K., Y. Takai, Y. Ogawa, S. Kimura, and Y. Nishizuka. 1982. Inhibitory action of adenosine $3^{\prime}, 5^{\prime}$-monophosphate on phosphatidylinositol turnover: difference in tissue response. Biochem. Biophys. Res. Commun. 104:105-112.

12. Watson, S. P., R. T. McConnell, and E. G. Lapetina. 1984. The rapid formation of inositol phosphates in human platelets by thrombin is inhibited by prostacyclin. J. Biol. Chem. 259:13199-13203.

13. Takenawa, T., J. Ishitoya, and Y. Nagai. 1986. Inhibitory effect of prostaglandin $E_{2}$, forskolin, and dibutyryl cAMP on arachidonic acid release and inositol phospholipid metabolism in guinea pig neutrophils. J. Biol. Chem. 261:1092-1098.

14. Takuwa, Y., N. Takuwa, and H. Rasmussen. 1988. The effects of isoproterenol on intracellular calcium concentration. J. Biol. Chem. 263:762-768.

15. Berridge, M. J., C. P. Downes, and M. R. Hanley. 1982. Lithium amplifies agonist-dependent phosphatidylinositol responses in brain and salivary glands. Biochem. J. 206:587-595.

16. Berridge, J. J. 1983. Rapid accumulation of inositol trisphosphate reveals that agonists hydrolyse polyphosphoinositides instead of phosphatidylinositol. Biochem. J. 212:849-858.

17. Torphy, T. J., C. Sheng, S. M. Peterson, R. R. Fiscus, G. A. Rinard, and S. E. Mayer. 1985. Inhibitory effect of methacholine on drug-induced relaxation, cyclic AMP accumulation, and cyclic AMPdependent protein kinase activation in canine tracheal smooth muscle. J. Pharmacol. Exp. Ther. 233:409-417.

18. Jones, C. A., J. M. Madison, M. Tom-Moy, and J. K. Brown. 1987. Muscarinic cholinergic inhibition of adenylate cyclase in airway smooth muscle. Am. J. Physiol. 253:C97-C104.

19. Zar, J. H. 1974. Biostatistical Analysis. Prentice-Hall, Inc., Englewood Cliffs, NJ. 620 pp.

20. Madison, J. M., C. A. Jones, R. M. Sankary, and J. K. Brown. 1987. Differential attenuating effects of prostaglandin $E_{2}$ on contractions of airway smooth muscle: role of adenylate cyclase inhibition. Am. Rev. Respir. Dis. 135:A88.

21. Triner, L., Y. Vulliemoz, and M. Verosky. 1977. Cyclic 3',5'adenosine monophosphate and bronchial tone. Eur. J. Pharmacol. 41:37-46.

22. Kato, H., J. Ishigoya, and T. Takenawa. 1986. Inhibition of inositol phospholipids metabolism and calcium mobilization by cyclic AMP-increasing agents and phorbol ester in neutrophils. Biochem. Biophys. Res. Commun. 139:1272-1278.

23. Lapetina, E. G. 1986. Incorporation of synthetic 1,2-diacylglycerol into platelet phosphatidylinositol is increased by cyclic AMP. FEBS (Fed. Eur. Biochem. Soc.) Lett. 195:111-114.

24. Monaco, M. E. 1987. Calcium and phosphoinositide cycle in WRK-1 cells, J. Biol. Chem. 262:147-151.

25. McDonough, P. M., D. Goldstein, and J. H. Brown. 1988. Elevation of cytoplasmic calcium concentration stimulates hydrolysis of phosphatidylinositol bisphosphate in chick heart cells: effect of sodium channel activators. Mol. Pharmacol. 33:310-315.

26. Colucci, W. S. 1986. Adenosine 3',5'-cyclic-monophosphatedependent regulation of alpha-adrenergic receptor number in rabbit aortic smooth muscle cells. Circ. Res. 58:292-297.

27. Gunst, S. J., J. Q. Stropp, and N. A. Flavahan. 1987. Analysis of receptor reserves in canine tracheal smooth muscle. J. Appl. Physiol. 62:1755-1758.

28. MacKay, D. 1981. An analysis of functional antagonism and synergism. Br. J. Pharmacol. 73:127-134.

29. Grandordy, B. M., F. M. Cuss, and P. J. Barnes. 1987. Breakdown of phosphoinositides in airway smooth muscle: lack of influence of antiasthmatic drugs. Life Sci. 41:1621-1627. 